\title{
Nanostructure Formation during Amorphous Carbon Films Deposition
}

\author{
Z. Rutkuniene*, L. Vigricaite And A. Grigonis \\ Kaunas University of Technology, Physics Department, Studentu 50, LT 51368, Kaunas, Lithuania
}

\begin{abstract}
Influence of $\mathrm{Cu}$ particles for the carbon nanostructures formation during a-C:H films deposition by plasma enhanced chemical vapor deposition method from pure acetylene gas plasma were analyzed in this work. Silicon wafer and $\mathrm{Cu}$ target were simultaneously bombarded by $\mathrm{Ar}^{+}$ions for the $\mathrm{Cu}$ particles deposition on the silicon before a-C:H films formation. It was obtained that hydrogenated silicon carbide forms on this defected $\mathrm{Si} / \mathrm{Cu}$ surface during the first stage of carbon film deposition. Structure of a: $\mathrm{C}-\mathrm{H}$ films and conditions of nanostructures formation depended on substrate temperature and $\mathrm{Cu}$ concentration in the film, then deposition time was $300 \mathrm{~s}$.
\end{abstract}

DOI: $10.12693 /$ APhysPolA.125.1303

PACS: $81.05 . u j, 81.15 .-\mathrm{z}, 78.20 .-\mathrm{e}, 82.80 . \mathrm{Gk}$

\section{Introduction}

Variety of carbon nanostructures and their unique properties allows discovering the new possibilities of applications. For example, differences of carbon nanotubes (CNT) structure induce changes of electrical properties and this phenomenon allows CNT to be usable for micro and nanoelectronics [1]. High temperature and specific conditions are required for nanostructures and nanotubes formation, so technological process becomes difficult and expensive. The possibilities to form carbon nanostructures vertically aligned or directly spinable CNT by plasma enhanced chemical vapor deposition (PECVD) method at low temperature become perspective and interesting for scientists and technologists [2]. In other case, semiconducting structures with useful electrical and optical properties formed in the nanocomposite a-C:H films with metal impurities also have high possibilities for application. It is well accepted that almost any metal nanoparticles can be used as catalyst for the growth of carbon nanotubes [3]. The possibility to localize the different concentration of metal impurities and grow nanostructures in one technological process during a-C:H film deposition would form applicable zones with different electrical, optical, and mechanical properties.

Formation of nanostructures in the a-C:H films using copper as their catalyst when silicon substrate temperature varied from $25^{\circ} \mathrm{C}$ till $250^{\circ} \mathrm{C}$ are presented in this work. Deposition of $\mathrm{Cu}$ and a-C:H films were going in succession during one technological process.

\section{Experimental setup}

a-C:H films were formed on silicon surface with metal clusters by PECVD method using $\mathrm{C}_{2} \mathrm{H}_{2}$ gas plasma. The temperature of silicon substrate was $25^{\circ} \mathrm{C}, 100^{\circ} \mathrm{C}$, and $250^{\circ} \mathrm{C}$. Duration of deposition was $45 \mathrm{~s}$ and $300 \mathrm{~s}$,

\footnotetext{
*corresponding author; e-mail: zivile.rutkuniene@ktu. It
}

bombarding ion energy was $200 \mathrm{eV}$. The copper was deposited before carbon film formation and the concentration $(\approx 5 \%)$ was dependent on the copper net bombardment conditions $\left(\mathrm{Ar}^{+}, E_{\mathrm{i}}-500 \mathrm{eV}, 180 \mathrm{~s}\right)$. The films optical properties were determined by null-ellipsometry (Gaertner L117 with a He-Ne laser $(632.8 \mathrm{~nm})$ ), Raman spectroscopy (RS) (Yvon Jobin spectrometer with a Spectra Physics YAG:Nd laser $(532.3 \mathrm{~nm}, 50 \mathrm{~mW}$, spot size $0.32 \mathrm{~mm})$ ). The experimental RS curves were fitted by few Gaussian-shape lines in the spectral range from $500 \mathrm{~cm}^{-1}$ to $1100 \mathrm{~cm}^{-1}$, from $1100 \mathrm{~cm}^{-1}$ to $2000 \mathrm{~cm}^{-1}$ and from $2000 \mathrm{~cm}^{-1}$ to $3000 \mathrm{~cm}^{-1}$. The surface morphology was analyzed by scanning electron microscopy JEOL JSM-5600, relative element concentrations were measured by Bruker AXS Microanalysis GmbH.

\section{Results and discussions}

$\mathrm{a}-\mathrm{C}: \mathrm{H}$ films were deposited during $45 \mathrm{~s}$ for the understanding of the first stage of carbon nanoclusters formation. The Raman spectra of films formatted when the substrate temperature was $25^{\circ} \mathrm{C}$ shows that few peaks at $518,560,616,813$, and at $1057 \mathrm{~cm}^{-1}$ were obtained in the $500-1100 \mathrm{~cm}^{-1}$ range (Fig. 1). First of them is characteristic for silicon, other two associate with $\mathrm{Cu}_{2} \mathrm{O}$ because this compound has related sub-peaks, such as 570,618 , or $624 \mathrm{~cm}^{-1}$ [4]. Wide peaks at $813 \mathrm{~cm}^{-1}$ and at $1057 \mathrm{~cm}^{-1}$ are related with silicon carboxyl bounds. Peak at $1057 \mathrm{~cm}^{-1}$ can be divided into two peaks near $945 \mathrm{~cm}^{-1}$ and $1036 \mathrm{~cm}^{-1}$. Peaks at $813 \mathrm{~cm}^{-1}$ and at $950 \mathrm{~cm}^{-1}$ show that $\mathrm{Si}-\mathrm{C}$ bound forms there. Peak at $950 \mathrm{~cm}^{-1}$ also can be due to the second order Raman spectrum from the Si substrate when films has high $s p^{3}$ fraction [5].

Low intensity of the peaks at the typical spectra range of a-C:H (1100-2000 $\left.\mathrm{cm}^{-1}\right)$ shows that formation of this film is burdened. Four weak peaks were obtained there: the $D$ peak at $1389 \mathrm{~cm}^{-1}, G$ peak at $1561 \mathrm{~cm}^{-1}$, and two additional peaks at $1252 \mathrm{~cm}^{-1}$ and $1778 \mathrm{~cm}^{-1}$. Shift of the $D$ and $G$ peaks into the higher means shows that more graphite like (GLC) film forms on the silicon surface. 


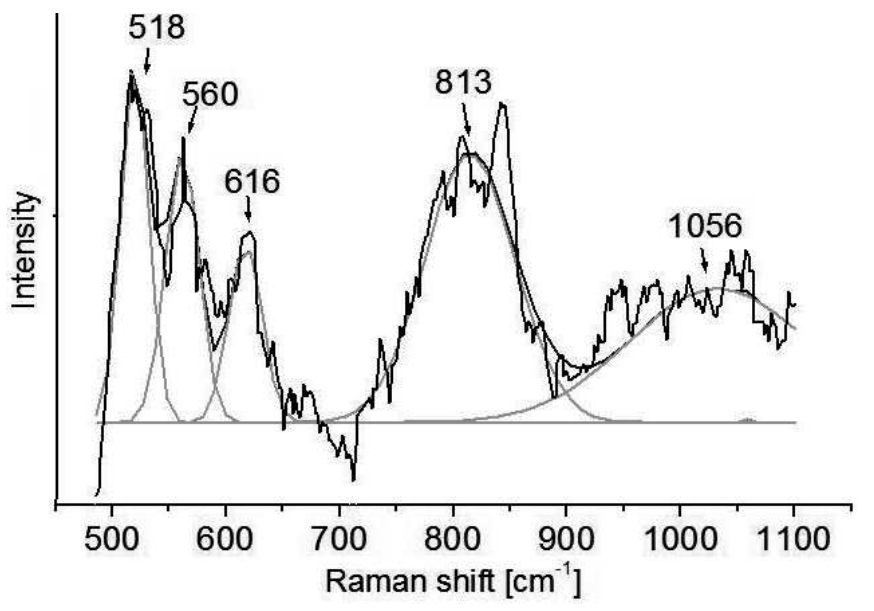

Fig. 1. Raman spectra of a-C:H film with copper impurities formed with $200 \mathrm{eV}$ ion energy at $25^{\circ} \mathrm{C}$ substrate temperature. Deposition duration $45 \mathrm{~s}$.

The peak at $1252 \mathrm{~cm}^{-1}$ is related to $\mathrm{CH}_{3}$ symmetric bending. Peak at $1778 \mathrm{~cm}^{-1}$ is the most interesting because it associates with three layer graphene (3LG) rhombohedral (ABC) structure. Cong et al. [6] obtained that peak at $1774 \mathrm{~cm}^{-1}$ is assigned to the overtone mode of the out-of-plane tangential optic (2oTO) mode. Low intensive $G^{\prime}(2 D)$ peak at $2690 \mathrm{~cm}^{-1}$ related with graphene also was obtained in the spectra. Peak for graphene is at $2680 \mathrm{~cm}^{-1}$, but Ferrari et al. [7] explain that the shifts of it into the higher mean depend on the number of graphene layers.

The low refractive index $(\approx 1.4)$, the high intensity of peaks associated with hydrogenated silicon carbide and weak peaks related with a-C:H suggest that $\mathrm{SiCOH}$ formation on the defected silicon surface is dominant in the first stage of the films deposition when the substrate temperature was $25^{\circ} \mathrm{C}$.

Thin GLC films with high concentration of stresses between graphite monolayers form on the top of $\mathrm{SiCOH}$. Stresses conditioning the breaking of weak bonds between graphite layers and multi-layer graphene can form. The films cracking during $45 \mathrm{~s}$ after quickly removing sample from vacuum to the environment confirm existence of the stress. For this reason all samples are always left about $120 \mathrm{~min}$ in the vacuum for stress relaxing.

The same peaks (expected $\mathrm{Cu}_{2} \mathrm{O}$ peaks) were obtained in the RS range from $500 \mathrm{~cm}^{-1}$ to $1100 \mathrm{~cm}^{-1}$ when the substrate temperature increases to $100^{\circ} \mathrm{C}$. Peaks in the $1100-2000 \mathrm{~cm}^{-1}$ range become more intensive. The $D$ and $G$ peaks shift to the lower means $\left(1295 \mathrm{~cm}^{-1}\right.$ and $1515 \mathrm{~cm}^{-1}$, respectively) and it confirms that concentration of $s p^{3}$ phase in the films is lower. The Raman peak at $1712 \mathrm{~cm}^{-1}$ is associated with $\mathrm{C}=\mathrm{O}$ stretching peak. Peak near $1250 \mathrm{~cm}^{-1}$ was not obtained, so it can be concluded that hydrogen is partially removed from films because of the heating. Relative concentration of carbon becomes lower in comparison with $25{ }^{\circ} \mathrm{C}(61 \%$ and $57 \%$, respec- tively), so film is thinner but having stronger expressed amorphous carbon phase. Refractive index $(\approx 1.6)$ is more characteristic for a-C:H than $\mathrm{SiCOH}$.

Differences in the Raman spectra were obtained only in the range from $1000 \mathrm{~cm}^{-1}$ to $2000 \mathrm{~cm}^{-1}$ when the sample temperature increases to $250{ }^{\circ} \mathrm{C}$. The four peaks were found there: $D$ at $1314 \mathrm{~cm}^{-1}, G$ at $1503 \mathrm{~cm}^{-1}$, peak associated $\mathrm{C}-\mathrm{H}$ in plane bending mode near $1169 \mathrm{~cm}^{-1}$ and peak at $1757 \mathrm{~cm}^{-1}$. The last of them is the result of the second-order Raman process involving the combination of the RBM and tangential mode ( $G$-line), which strongly supports the growth of single wall nanotubes (SWNTs) [8]. Scanning electron microscopy (SEM) pictures show the first stage of nanoclusters formation (Fig. 2). So, high temperature, Cu clusters, and graphite-like carbon film are the conditions for the nanostructures formation in the first stage of process.

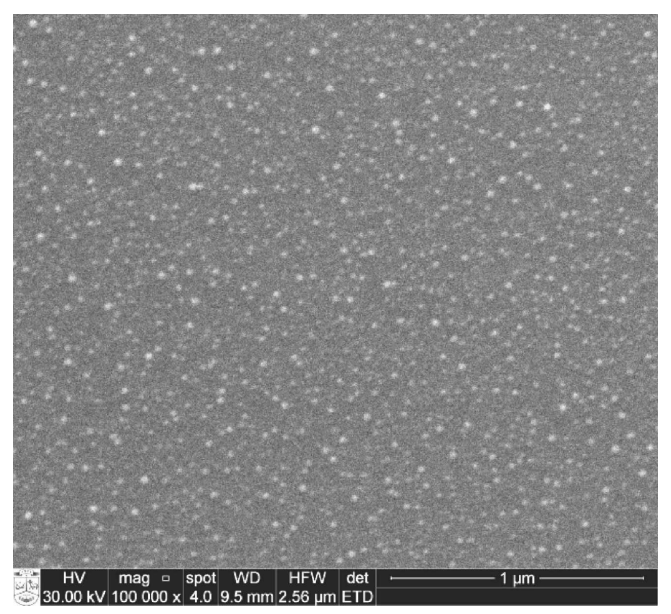

Fig. 2. SEM images of a-C:H film with copper impurities formed with $200 \mathrm{eV}$ ion energy at $250{ }^{\circ} \mathrm{C}$ substrate temperature. Deposition duration $45 \mathrm{~s}$.

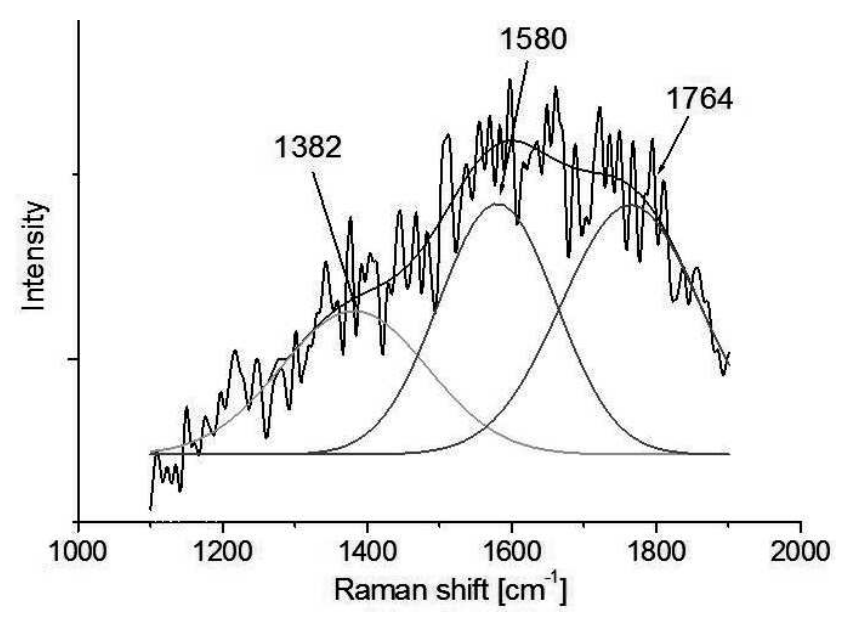

Fig. 3. Raman spectra of a-C:H film with copper impurities formed with $200 \mathrm{eV}$ ion energy at $25^{\circ} \mathrm{C}$ substrate temperature. Deposition duration $300 \mathrm{~s}$. 
The Raman spectra in the $500-1000 \mathrm{~cm}^{-1}$ range were changed when duration of film deposition increases to 300 s. Peaks related with hydrogenated silicon carbide were not obtained in RS spectra, the refractive indexes were about 1.7 for all films in all temperature ranges. Typical $D\left(1382 \mathrm{~cm}^{-1}\right)$ and $G$ peaks $\left(1580 \mathrm{~cm}^{-1}\right)$ with additional peak at $1764 \mathrm{~cm}^{-1}$ become dominant when the substrate temperature was low $\left(25^{\circ} \mathrm{C}\right)$ (Fig. 3). Formation of carbon nanostructures at $25^{\circ} \mathrm{C}$ becomes understandable (Fig. 4) because of formation of graphene layers in the first stage (after $45 \mathrm{~s}$ ) were obtained. $\mathrm{Cu}$ relative concentration in the film was $\approx 1.2 \%$ (carbon $69.7 \%$ ).

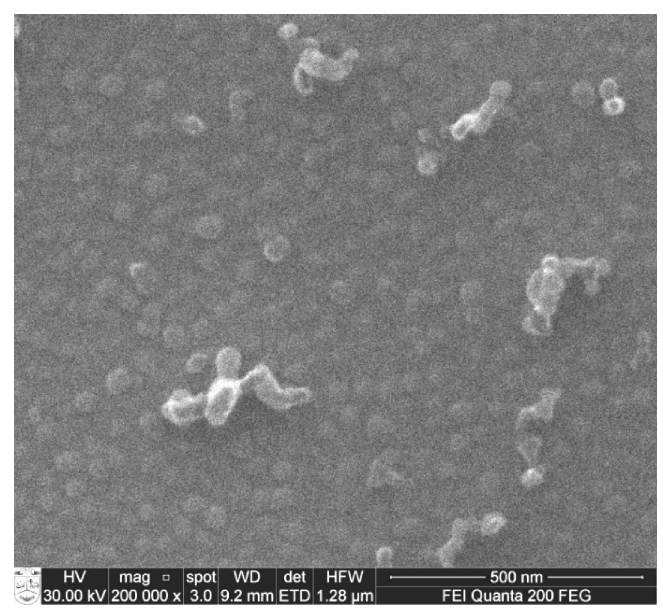

Fig. 4. SEM images of a-C:H film with copper impurities formed with $200 \mathrm{eV}$ ion energy at $25^{\circ} \mathrm{C}$ substrate temperature. Deposition duration $300 \mathrm{~s}$.

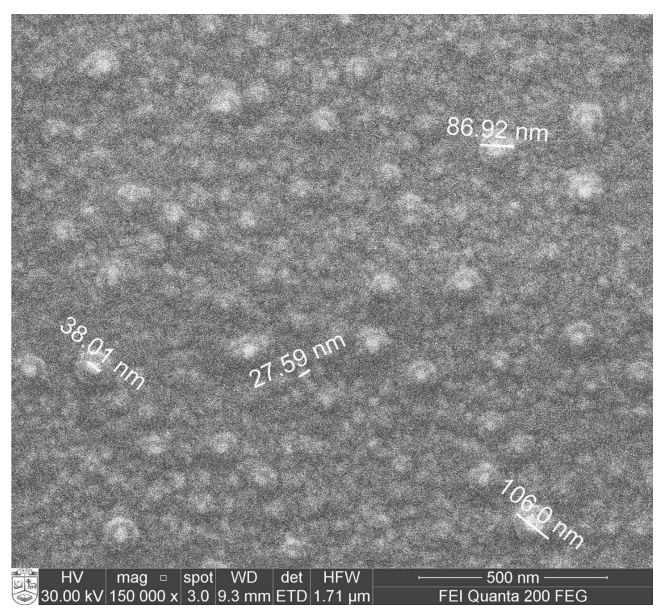

Fig. 5. SEM images of a-C:H film with copper impurities formed with $200 \mathrm{eV}$ ion energy at $250{ }^{\circ} \mathrm{C}$ substrate temperature. Deposition duration $300 \mathrm{~s}$.

The $D$ and $G$ peaks with increasing substrate temperatures to $100{ }^{\circ} \mathrm{C}$ are shifted to the lower means as in the short time case, but peak of $\mathrm{C}=\mathrm{O}$ stretching becomes weak. Formation of nanostructures was not obtained and related concentration of $\mathrm{Cu}$ drastically decreased to $0.27 \%$. Thickness of films is higher $(194 \mathrm{~nm})$ than $25^{\circ} \mathrm{C}$ $(78 \mathrm{~nm})$, but it is not so important in comparison with $\mathrm{Cu}$ concentration changes (thickness was changed twice, $\mathrm{Cu}$ about four times). Decrease of $\mathrm{Cu}$ concentration can be conditioned by the diffusion to the silicon bulk because coefficient of diffusion increases with increasing temperature $\left(1.1 \times 10^{-9} \mathrm{~cm}^{2} / \mathrm{s}\right.$ at $25^{\circ} \mathrm{C}$ and $2.4 \times 10^{-8} \mathrm{~cm}^{2} / \mathrm{s}$ at $100^{\circ} \mathrm{C}$ ).

Rudiments of CNT formation were obtained in the early stage when the substrate temperature was $250^{\circ} \mathrm{C}$ (Fig. 1) and they continued growing during long deposition process (Fig. 5). Cu concentration (1.91\%) and the temperature are sufficient for nanostructures formation. It is important that diameter of $\mathrm{Cu}$ clusters is about $50 \mathrm{~nm}$, so only nano onion-like structures can form on the surface (Fig. 5). Diameter of metal clusters necessary for SWNT or MWNT catalyst is about $\approx 1-5 \mathrm{~nm}$ and $\approx 20-50 \mathrm{~nm}[9]$.

\section{Conclusions}

It was obtained that hydrogenate silicon carbide forms on the defected silicon surface during first stage of a-C:H deposition. Thin GLC film is on the top of this $\mathrm{SiCOH}$ layer. Stresses in the thin GLC film can produce multi-layer graphene formation and it conditioned nanostructure growing at the room temperature. Carbons microstructures begin forming also when the temperature of silicon surface with carbon cluster is $250^{\circ} \mathrm{C}$.

\section{Acknowledgments}

This article was prepared under partial support of the European Social Fund Agency implementing measure VP1-3.1-MM-08-K of the Human Resources Development Operational Programme of Lithuania 2007-2013 3rd priority "Strengthening of capacities of researchers and scientists" (project No. VP1-3.1-MM-08-K-01-013).

\section{References}

[1] M. Meyyappan, L. Delzeit, A. Cassell, D. Hash, Plasma Sourc. Sci. Technol. 12, 205 (2003).

[2] S.H. Lim, Z. Luo, Z. Shen, J. Lin, Nanoscale Res. Lett. 5, 1377 (2010).

[3] G. Hong, Y. Chen, P. Li, J. Zhang, Carbon 50, 2067 (2012).

[4] Z.H. Gan, G.Q. Yu, B.K. Tay, C.M. Tan, Z.W. Zhao, Y.Q. Fu, J. Phys. D, Appl. Phys. 37, 81 (2004).

[5] W.R. Gilkes, S. Prawer, K.W. Nugent, J. Robertson, H.S. Sands, Y. Lifshitz, X. Shi, J. Appl. Phys. 87, $7283(2000)$

[6] C. Cong, T. Yu, K. Sato, J.Z. Shang, R. Saito, ACS Nano 5, 8760 (2011).

[7] A.C. Ferrari, J.C. Meyer, V. Scardaci, C. Casiraghi, M. Lazzeri, F. Mauri, S. Piscanec, D. Jiang, K.S. Novoselov, S. Roth, A.K. Geim, Phys. Rev. Lett. 97, 187401 (2006).

[8] Md. Shajahan, Young Hwan Mo, Kee Suk Nahm, Korean J. Chem. Eng. 20, 566 (2003).

[9] Gore, Anup Sane, in: Flame Synthesis of Carbon Nanotubes, Carbon Nanotubes - Synthesis, Characterization, Applications, Ed. Siva Yellampalli, InTech, 2011. 